\title{
Price Risk Measurement of China's Soybean Futures Market Based on the VAR-GJR-GARCH Model
}

\author{
Chuan-hui Wang $\mathbb{D},{ }^{1}$ Li-ping Wang, ${ }^{1}$ Wei-feng Gong $\mathbb{D}^{1,2}$ Hai-xia Zhang $\mathbb{D}^{1},{ }^{1}$ and Xia Liu $\mathbb{D}^{1}$ \\ ${ }^{1}$ School of Economics, QuFu Normal University, Rizhao 276826, China \\ ${ }^{2}$ School of Economics and Management, Nanjing University of Aeronautics and Astronautics, Nanjing 211006, China \\ Correspondence should be addressed to Wei-feng Gong; gongweifeng0539@163.com
}

Received 25 June 2021; Revised 10 October 2021; Accepted 8 November 2021; Published 10 December 2021

Academic Editor: Shahzad Sarfraz

Copyright (C) 2021 Chuan-hui Wang et al. This is an open access article distributed under the Creative Commons Attribution License, which permits unrestricted use, distribution, and reproduction in any medium, provided the original work is properly cited.

\begin{abstract}
As one of the main forces in the futures market, agricultural product futures occupy an important position in China's market. As China's futures market started late and its maturity was low, there are many risks. This study focuses on the Dalian soybean futures market. Dynamic risk measurement models were established to empirically analyze risk measurement problems under different confidence levels. Then, the conditional variance calculated by the volatility model was introduced into the value-at-risk model, and the accuracy of the risk measurement was tested using the failure rate test model. The empirical results show that the risk values calculated by the established models at the $99 \%$ and $95 \%$ confidence levels are more valuable through the failure rate test, and the risk of China's soybean futures market can be measured more accurately. The characteristics of "peak thick tail" and "leverage effect" are added to the combination model to calculate the conditional variance more accurately. The failure rate test method is used to test the model, which enriches the research problem of risk measurement.
\end{abstract}

\section{Introduction}

In the bulk commodity trade, soybeans, as an agricultural product with a large demand in China, have a prominent price fluctuation problem. In addition, China's soybean imports are at a disadvantage. China has become the world's largest importer. China's soybean futures market started late, the maturity was low, and the degree of risk was high, so the risk problem was a concern. Since 1992, the import of soybeans in China has been increasing greatly, accelerating even more in 1995. Since 1996, China has become a major net importer of soybeans worldwide. To optimize the soybean supply structure, China has implemented the agricultural policy of "reducing corn and increasing soybeans" since 2016. When trade frictions between China and the United States intensified in 2018, the United States increased import tariffs by $25 \%$, increasing import costs, and Russia and Canada increased exports to China. In 2019, the Ministry of Agriculture and Rural Affairs of China decided to implement the Soybean Revitalisation Plan and put forward six subsidy policies to support soybean development. In 2020, the central government of China stated that China should increase its support for the promotion of highyield soybean varieties and the new agronomic promotion of maize and soybean intercropping. Agricultural futures occupy an important position in China's market as one of the main forces of the futures market. In the early days, agricultural products were traded on the spot, with extremely violent price fluctuations. Later, futures were adopted to regulate the market system and avoid risks to a certain extent. The Chicago Board of Trade was formally established in 1848. Standard futures contracts replaced forward contracts. The margin system was implemented, and agricultural product trading entered the era of standardized futures trading. In 1993, China established the Dalian Commodity Exchange (DCE). As the main force of agricultural products, soybean futures are listed in China's first batch. Agricultural futures not only affect the development of the national economy but also have a decisive significance in downstream futures. The maturity of the soybean futures market in China 
is not very high, and many problems still exist. The factors affecting the fluctuation of soybean futures prices should be comprehensively discussed, and the risk measurement of the soybean futures market in China should be systematically studied. All countries have taken effective measures to protect the soybean industry to solve the problem of food security. This approach avoids system risk to a certain extent while alleviating the Chinese economic changes caused by international soybean price changes. The research on China's soybean futures market can not only deeply analyze the problems existing in the soybean futures market but also adopt the corresponding control policies in a timely manner to avoid certain risks. The research presented in this paper has great practical significance for solving the problem of soybean futures risk measurement.

With the continuous development of economic integration, the scale of the financial market continues to expand, and its risk increases. Some foreign financial markets have matured earlier. In the early stage, qualitative analysis was mainly used to study risk measurement from a macroperspective, and in the 1930s, models were adopted to carry out quantitative research. Markowitz first proposed a method of sample variance to measure risks. With the rapid development of financial derivatives, the value-at-risk (VAR) model has become one of the main models for measuring risks [1]. The main methods to measure the VAR value include the covariance method, the historical simulation method, and the Monte Carlo method.

The variance-covariance method is a risk-metrics model proposed by the J.P. Morgan Group. The basic idea is to assign different weights according to the distance between the time series and the current time. The closer the distance is to the current event, the richer the market information will be, the greater the weight will be, and the greater the impact on the current price will be. This model assumes that the rate of return must follow a normal distribution, whereas in practical applications, the rate of return often has the characteristics of sharp peaks and thick tails. If there is a significant increase or decrease in the value of the VAR, the current risk level will be underestimated. To remedy this defect, Bollerslev used the generalized autoregressive conditional heteroskedasticity (GARCH) model to calculate the value of VAR [2]. All such methods use variance to represent the volatility of the market, and they are collectively known as the variance-covariance method.

In recent years, the VAR combination model has been greatly developed. Many scholars have applied this model to securities, funds, futures, and other fields. Zou et al. showed that the VAR-GARCH $(1,1)$ model can be used to accurately estimate the risk of the Shanghai stock market [3]. Liu and $\mathrm{Yu}$ concluded that China can effectively avoid risks by learning from the price avoidance methods of the American agricultural futures market when studying the risk avoidance measures of foreign futures markets [4]. Jiang and Qu used the VAR and GARCH models to study the trading data of simulated stock index futures and showed that this method could effectively estimate the value of risk, with only a small error between the method and the actual risk [5]. Based on the GARCH model, Yang discussed the VAR calculation method of logarithmic return under generalized error distribution (GED), t-distribution, and normal distribution, and the research results showed that the VAR value of the GARCH model under GED-distribution reflects the fund risk more accurately [6]. Zhang et al. compared the different performance of risk measurement of the conditional autoregressive value at risk (CAVIAR) and GARCH-GED models under different prediction intervals and confidence levels, indicating that the combined extreme value theory (EVT)-CAVIAR model is more robust and accurate for carbon market risk prediction [7]. Tao and Chen built a VAR-GARCH model to explore the pressure degree of RMB currency on foreign exchange in different states [8]. Yang and Yang conducted an empirical analysis of the relationship between the interest rate of net loans, Shibor, and private lending rates by constructing the VAR-GARCH-BEKK (BEKK is named after Baba, Engle, Kraft, and Kroner) model to provide suggestions for financial risk prevention [9]. Karmakar and Paul predicted the VAR and conditional VAR (CVAR) of three market portfolios using the CGARCHEVT-copula model to determine the optimal portfolio model [10]. Lin et al. made risk measurement more accurate based on the VAR-GARCH model family [11]. Gong et al. studied the tail dependence of VAR and portfolio risk for the crude oil futures market [12]. Liu and Liu studied the tail risk spillover effect of different types of financial institutions [13]. Liang introduced the GJR model with a negative information correction term to fit the expected volatility and expected drift of the historical return rates of rebar spot and futures, used the Monte Carlo method to calculate the VAR value of the hedging portfolio, and established the hedging ratio VAR value surface model to solve the optimal hedging ratio in reverse [14]. Alexander et al. believe that when the prediction range is larger than the frequency of the GARCH model, it usually requires a time-consuming simulation of summary income distribution, which can be achieved quickly based on the new GARCH-VAR formula, and the data from different financial assets can be accurately analyzed using the analysis moments of symmetric and asymmetric GJR-GARCH processes to obtain accurate GARCH-VAR predictions at multiple significance levels [15].

According to the above analysis, domestic and foreign scholars have mainly studied the risk measurement VAR model of the soybean futures market in recent years and have achieved rich research results. The risk research of the soybean futures market has focused on qualitative analysis, but now it begins to change to quantitative analysis. GARCH models with different distributions are mostly used to measure conditional standard deviations without considering the characteristics of price fluctuations. However, the VAR measurement using combined models will improve the accuracy. The use of the model is relatively simple and requires less analysis, which is not currently involved in innovative methods at the present stage. However, using a combined model to measure the VAR will improve the accuracy. In this study, the quantitative analysis method was adopted, considering the characteristics of price volatility clustering, leverage effect, peak, and thick tail; the combined VAR-GARCH model and VAR-GJR-GARCH model were 
constructed under different confidence levels for risk measurement research, and the accuracy of the model using the failure rate test method was verified.

\section{Statistical Analysis of Basic Characteristics of Chinese Soybean Futures Market}

2.1. Data Collection and Selection. In recent years, China's soybean futures contracts have become more active on the DCE, so this study chooses those contracts for research. The volatility and risks in China's soybean futures market are mainly caused by fluctuations in price and yield rate, so price is selected as the research object. Because several contracts with different delivery months will participate in trading on the same trading day, the same futures product will have different trading prices on the same trading day. Therefore, in the selection of data, both the discontinuity of futures market prices and the price of futures contracts should be considered.

To make the trading data more representative and the research on the problem more convincing, this study chooses contracts with large settlement prices, trading volumes, and open positions in trading contracts, among which the contract data of A1505, A1605, A1705, A1805, A1905, and A2005 are selected. If there are two contracts in a day at the same time, according to the above choices, the paper chooses a contract with a large trading volume and open position to constitute the main contract in China's soybean futures market. The settlement price of the contract as transaction data was selected to form a continuous time series. The soybean futures available for delivery on the DCE of China include Yellow Soybean No. 1 and Soybean No. 2. As a non-GM soybean, Yellow Soybean No. 1 has a good representation in studying the price fluctuation of China's soybean futures market, so the main contract of Yellow Soybean No. 1 is chosen as the research object. In this study, a total of 1,219 sample data were selected from 31 December 2014 to 31 December 2019. A model was established and analyzed for the above data. Descriptive statistical analysis was conducted on the time-series data of the Chinese soybean futures yield. The return rate series data were obtained by logarithmic processing of the soybean futures' settlement price data in China. The formula used to calculate the rate of return was as follows:

$$
R_{t}=\ln P_{t}-\ln P_{t-1},
$$

where $R_{t}$ represents the yield of the day, $P_{t}$ represents the settlement price of the day, and $P_{t-1}$ represents the settlement price of the previous day. The time series of the rate of return was obtained and analyzed.

2.2. Statistical Characteristics of Yield Rate. Through logarithmic processing of the sample data, basic statistical results were obtained. Figure 1 shows a line graph of the daily return rate fluctuation of the main soybean futures contract in China.

As shown in Figure 1, the yield series of the soybean futures market in China has a fluctuation agglomeration effect, which usually means that the yield series will have an autoregressive conditional heteroscedasticity (ARCH) effect.

The statistics of the daily return series of China's soybean futures contracts are obtained by a statistical test of the return series of China's soybean futures market. This is shown in Table 1.

As shown in Table 1, the skewness of the daily return series of Chinese soybean futures is $S=1.436>0$ and kurtosis $K=14.74>3$. This skewness is skewed to the right, relative to the normal distribution. Therefore, the yield sequence of Chinese soybean futures shows the characteristics of "sharp peak and thick tail." In addition, the Jarque-Bera statistic was 7417, and the corresponding $P$ value was 0 . Therefore, the null hypothesis is rejected, indicating that the return rate series does not follow a standard normal distribution. Therefore, the $t$-test, $F$-test, and other tests suitable for normal distribution cannot be used to test the rate of return.

The futures market is a financial market, and the volatility of the financial market is relatively complex. The time series of the financial market is independent, and the variance is a fixed constant series. Volatility persistence is also known as the long-term memory of volatility. It refers to a long-term financial time series that has a special non-linear relationship. The longer the time interval, the stronger the correlation between the numerical values. This characteristic makes continuous movement of the sequence in the same direction, through a waning change direction. The long-term accumulation of time is caused by fluctuations in sustainability. Therefore, in the financial market, transaction information in the past period will have a long-term and lasting impact on information in the future. The financial time series is characterized by sharp peaks and thick tails and does not obey the standard normal distribution. Therefore, $t$ tests, F-tests, and other tests suitable for normal distribution cannot be used to carry out relevant tests, meaning that the traditional linear regression method cannot be used to solve this problem. As financial time series generally have heteroscedasticity, the ARCH model is considered for analysis. Therefore, stationarity tests and autocorrelation tests are also required for the sample time return series.

2.3. Test of Yield Series. Before establishing the model for the return rate data, it is necessary to conduct stationarity, autocorrelation, partial autocorrelation, and ARCH effect tests to confirm the practical significance of the subsequent model.

2.3.1. Rate of Return Stability Test. If the sample sequence data are non-stationary, even if there is no correlation between variables, the regression results will have a high degree of fit and even lead to pseudo-regression. Therefore, a stationarity test should be conducted before establishing the model. There are many methods for the sequence stationarity test; the Dickey-Fuller (DF) and augmented Dickey-Fuller (ADF) tests are widely used. When the sequence has a high-order lag correlation, the DF test violates the assumption that the random disturbance terms are 


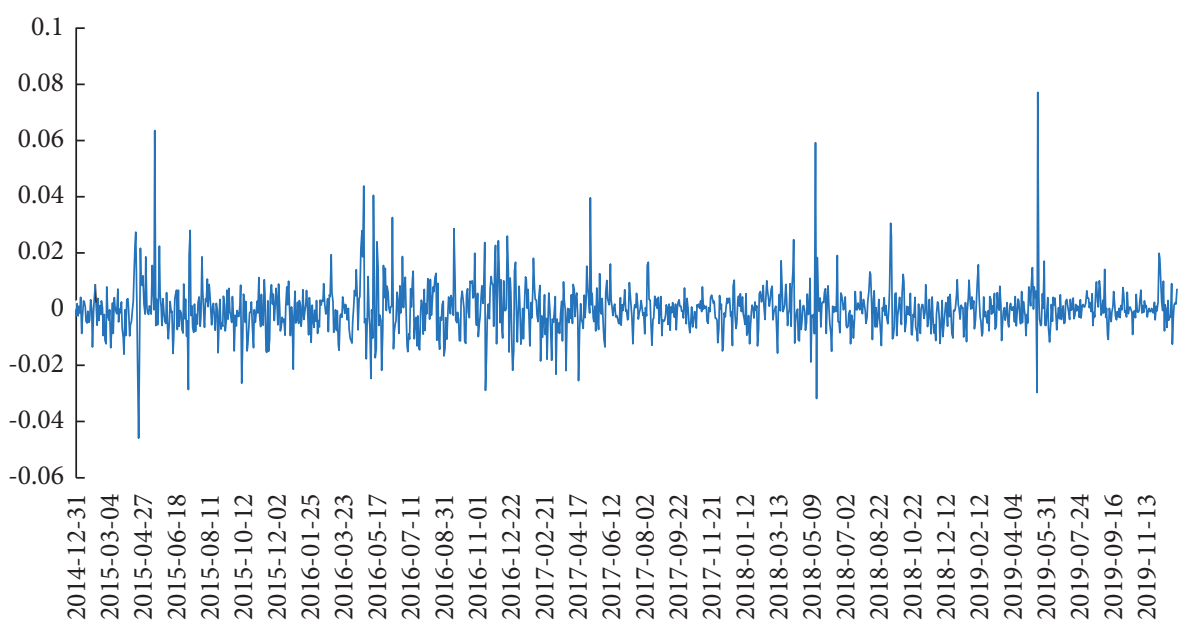

FIgure 1: The daily yield fluctuation of China's soybean futures market.

TABLE 1: Daily yield series of China's soybean futures' main continuous contracts.

\begin{tabular}{lcccrr}
\hline Statistic & Standard deviations & Skewness & Kurtosis & Jarque-Bera statistics & $P$ value \\
\hline Soybean futures daily return series & 0.0086258 & 1.436 & 14.74 & $\leq 417$ & 50.0000 \\
\hline
\end{tabular}

independently and identically distributed. Therefore, the ADF unit root test was used to test the stationarity of highorder sequences. According to the critical value of the t-statistic at the confidence levels of $1 \%, 5 \%$, and $10 \%$, if the test $\mathrm{t}$-statistic is less than the critical value, the null hypothesis is rejected, and the sample sequence does not have a unit root and is stable. Otherwise, the null hypothesis is accepted, and the sample has a non-stationary sequence. Simultaneously, the size of the $P$ value in the ADF test can be analyzed. When $P$ is greater than 0.05 , the null hypothesis is accepted, which means that the sample sequence has a unit root and a non-stationary sequence. Otherwise, it is a stationary sequence, and the closer the $P$ value is to zero, the higher the data stationarity is, and the more accurate the result is.

The unit root test was performed on the time-series data, and the results are shown in Table 2 .

As shown in Table 2, the t-statistic value of the ADF test is -30.923 , which is far less than the critical value at the significance level of $1 \%, 5 \%$, and $10 \%$. The $P$ value corresponding to the yield series is 0 , so the null hypothesis is rejected. There is no unit root in the daily yield series of Chinese soybean futures, which is a stationary series that is suitable for empirical research.

\subsubsection{Test of Autocorrelation and Partial Autocorrelation of} Return Rate. The series of returns changes with time, presenting kurtosis and skewness. The returns of successive adjacent periods are not independently and identically distributed, which is called the autocorrelation of returns. If the rate of return is autocorrelated, residual autocorrelation will result in inaccurate empirical results. Therefore, it is necessary to conduct an autocorrelation test on the rate of return series. If the autocorrelation and partial
TABLE 2: Stability test of China's soybean futures yield series.

\begin{tabular}{lccc}
\hline & & $t$-statistic & Prob. $^{*}$ \\
\hline $\begin{array}{l}\text { Augmented Dickey-Fuller test } \\
\text { statistic }\end{array}$ & & -30.923 & $\leq 0.0000$ \\
& $1 \%$ level & -3.430 & \\
Test critical values & $5 \%$ level & -2.860 & \\
& $10 \%$ & -2.570 & \\
& level & & \\
\hline
\end{tabular}

autocorrelation graphs have no obvious truncation or trailing phenomena, there will be no autocorrelation or partial autocorrelation.

Autocorrelation and partial autocorrelation tests were carried out on the yield data of the Chinese soybean futures market. The results show that there is high-order non-autocorrelation in the daily yield series, and there is no obvious truncation or trailing phenomenon in the selected yield series. Therefore, there is no autocorrelation or partial autocorrelation in the yield series of the Chinese soybean futures market.

2.3.3. ARCH Effect Test. To test whether the residual series of return rate has an $\mathrm{ARCH}$ effect, that is, to test whether the residual has conditional heteroscedasticity, this study chose the commonly used Lagrange multiplier (LM) test. Engel proposed the LM test to test whether the ARCH effect exists in residual sequences. The original hypothesis of the test was that there was no ARCH effect in residual sequences up to order $Q$, and the regression equation was expressed as follows:

$$
V a R=-Z_{c} \sigma_{\rho} \sqrt{\Delta t}
$$

Two statistics are output through this test: the F statistic is used to test the joint significance for all lagging residual 
square terms; the $T \times R^{2}$ statistic represents the product of sample size and goodness of fit of the test regression equation. Under the condition that the null hypothesis holds, the sample distribution of the F statistic is not clear, but the LM test statistic asymptotically obeys the distribution $\chi^{2}(q)$. The ARCH-LM test results of the residual sequences are shown in Table 3.

As shown in Table 3 , the $P$ value corresponding to each statistic of the residual squared lag of order $1-5$ is 0 , indicating that all the lagging residual squares are jointly significant. The $P$ value of the ARCH effect test is 0 , so the null hypothesis is rejected. The residual sequence has conditional heteroscedasticity and an ARCH effect.

\section{Empirical Study on the Price Risk Measurement of China's Soybean Futures Market}

The price of China's soybean futures fluctuated greatly, the uncertainty was strong, and the risk was high. Therefore, the risk measurement of the Chinese soybean futures market prices was studied by establishing VAR-GARCH and VAR-GJR-GARCH portfolio models. First, the GARCH and GJR-GARCH models were constructed to measure the conditional variance. Then, a dynamic risk measurement model was constructed, and the variance values calculated by the GARCH and GJR-GARCH models were introduced into the VAR model to measure the risk value. Finally, the failure rate test of the VAR was conducted to observe whether the risk value was effective mainly through the failure rate. The main process is illustrated in Figure 2.

3.1. Empirical Analysis of Yield Characteristics Based on GARCH Model. To reduce the error and variability of the data, the yield series is standardized, and the GARCH model is constructed to depict the volatility of soybean futures prices in China.

3.1.1. GARCH Model Construction. In the GARCH $(p, q)$ model, $P$ is the order of the autoregressive GARCH term and $q$ is the order of the ARCH term, in which GARCH $(1,1)$ has the highest frequency of application, mainly because GARCH $(1,1)$ is relatively simple and has a great advantage in calculating the conditional variance and conditional mean of the time series. In the process of practical application, it is found that GARCH $(1,1)$ does not exhibit high-order risks, so GARCH $(1,1)$ is selected as the return rate sequence (Lin et al.). The regression equation is expressed as follows:

$$
\sigma_{t}^{2}=\alpha_{0}+\alpha_{1} \varepsilon_{t-1}^{2}+\beta_{1} \sigma_{t-1}^{2} .
$$

3.1.2. Empirical Results and Analysis of Yield Characteristics of GARCH Model. The GARCH $(1,1)$ model is constructed for China's soybean futures price, and the results are shown in Table 4.

The variance of the conditional equation in the GARCH $(1,1)$ model is
TABLE 3: ARCH-LM test results of residual series.

\begin{tabular}{lccc}
\hline Lags $(P)$ & $\mathrm{Chi}^{2}$ & $\mathrm{df}$ & Prob $>\mathrm{chi}^{2}$ \\
\hline 1 & 24.996 & 1 & $\leq 0.0000$ \\
2 & 25.293 & 2 & $\leq 0.0000$ \\
3 & 26.459 & 3 & $\leq 0.0000$ \\
4 & 26.457 & 4 & $\leq 0.0000$ \\
5 & 28.198 & 5 & $\leq 0.0000$ \\
\hline
\end{tabular}

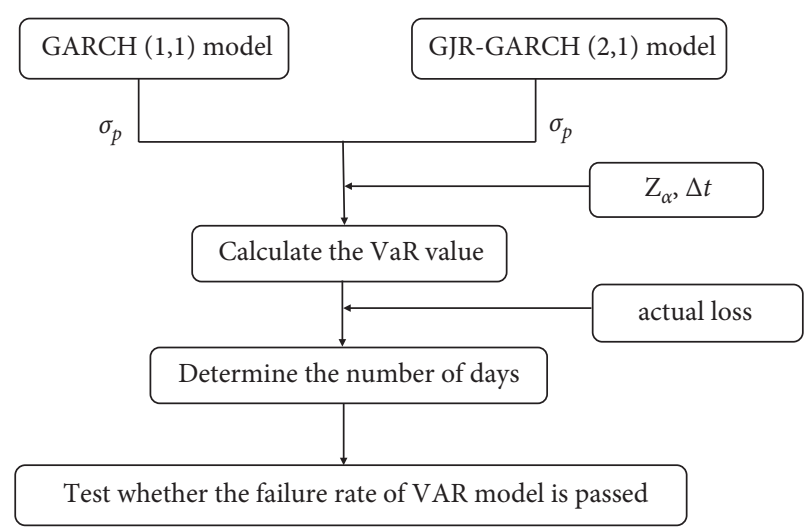

Figure 2: Process chart of dynamic risk measurement of China's soybean futures price.

TABLE 4: Estimation of GARCH $(1,1)$ model.

\begin{tabular}{lcccc}
\hline & $\alpha_{0}$ & $\alpha_{1}$ & $\beta_{1}$ & $\alpha_{1}+\beta_{1}$ \\
\hline $\begin{array}{l}\text { Coefficient } \\
\text { estimation }\end{array}$ & 0.0001624 & 0.1424091 & 0.8435093 & 0.9859184 \\
$Z$ value & 8.37 & 15.71 & 110.39 & \\
$P$ value & 0.000 & 0.000 & 0.000 & \\
\hline
\end{tabular}

$$
\sigma_{t}^{2}=0.0001624+0.1424091 \varepsilon_{t-1}^{2}+0.8435093 \sigma_{t-1}^{2} .
$$

The Akaike information criterion (AIC) value is -3217.4 , the Bayesian information criterion (BIC) value is -3197 , and the logarithmic likelihood value is 1612.7 .

As can be seen from Tables 3 and 4, the parameter estimates of ARCH and GARCH terms in the conditional variance equation are highly significant at the $5 \%$ significance level; the parameter estimates are all greater than zero, which meets the requirement of non-negative conditional variance, indicating that the price fluctuations in China's soybean futures market are characterized by volatility aggregation; the estimated coefficients of the $\mathrm{ARCH}$ and GARCH terms are 0.1424091 and 0.8435093 , respectively, and the sum of coefficients is less than 1 , which satisfies the constraint conditions of model parameters. This indicates that the conditional variance of the random error term can converge to unconditional variance, and the fluctuation process is stationary; as the sum of the coefficients is very close to 1 , it indicates that the impact of the early shock on the subsequent conditional variance is lasting and will affect future fluctuations for a long time. Therefore, we believe that China's soybean futures market has high volatility and high market risk. This also describes the current situation of China's soybean futures: China's soybeans are mainly 
imported, and the change of international political situation will cause a huge impact on China's soybean futures market.

The ARCH-LM test was performed on the GARCH $(1,1)$ model with a lag of 10 orders, and the results are shown in Table 5.

As can be seen from Table 5, the R-squared equals 14.58331. The $P$ value of the 10 -order residual lag is 0.1479 and is greater than 0.05 . This means that the ARCH effect does not exist in the conditional variance. The model passed the test, so the conditional heteroscedasticity of the daily return series of soybean futures contracts was eliminated after the application of the GARCH model.

3.2. Empirical Analysis of Yield Characteristics Based on GJRGARCH Model. The leverage effect is common in financial time series, so the asymmetric ARCH model and GJRGARCH model are constructed to describe the fluctuation characteristics of soybean futures prices.

3.2.1. GJR-GARCH Model Construction. As financial time series are prone to leverage effect, this study selects the GJRGARCH model with asymmetry to measure the advantages and disadvantages of the model according to AIC and BIC and maximum likelihood value. The commonly used GJRGARCH model is GJR-GARCH $(1,1)$. The smaller the value of GJR-GARCH $(1,2)$, GJR-GARCH $(2,1)$, and GJR-GARCH $(2,2)$, the smaller the model error. The fitting effect of the model is better when the maximum likelihood value is larger, and the results of the GJR-GARCH $(p, q)$ model are shown in Table 6.

As shown in Table 6, the GJR-GARCH $(2,1)$ model has the smallest AIC and BIC values, and the GJR-GARCH $(2,1)$ model has the largest maximum likelihood value. Therefore, it is believed that the GJR-GARCH $(2,1)$ model has the advantages of small error and good fitting effect.

3.2.2. Empirical Results and Analysis of Yield Characteristics of GJR-GARCH Model. The GJR-GARCH $(2,1)$ model was constructed to estimate Chinese soybean futures price. The regression equation is expressed as follows:

$$
\sigma_{t}^{2}=\alpha_{0}+\alpha_{1} \varepsilon_{t-1}^{2}+\alpha_{2} \varepsilon_{t-1}^{2}+\beta_{1} \sigma_{t-1}^{2}+\gamma \varepsilon_{t-1}^{2} I_{t-1},
$$

where $I_{t-1}$ is the dummy variable.

$$
I_{t-1}= \begin{cases}1, & \varepsilon_{t-1} \geq 0 \\ 0, & \varepsilon_{t-1}<0\end{cases}
$$

In (6), good news or positive shock is $\varepsilon_{t-1}>0$, and bad news or negative shock is $\varepsilon_{t-1}<0$. It has different impact on conditional variance $\sigma_{t}^{2}$, the impact of the front is $\alpha_{1} \varepsilon_{t-1}^{2}$, and the impact of the latter is $\left(\alpha_{1}+\gamma\right) \varepsilon_{t-1}^{2}$. When $\gamma<0$, it indicates the existence of asymmetric effect. When $\gamma=0$, it indicates that there is no asymmetric effect.

The results of estimation of the GJR-GARCH $(2,1)$ model are shown in Table 7.

By constructing the GARCH and GJR-GARCH models, the price fluctuation of China's soybean futures market has
TABLe 5: ARCH-LM test of GARCH $(1,1)$.

\begin{tabular}{lccc}
\hline$F$ value & 1.462706 & $P$ value & 0.1479 \\
\hline Obs $*$ R-squared & 14.58331 & Prob. chi-square (10) & 0.148 \\
\hline
\end{tabular}

the characteristics of fluctuation aggregation and persistence. Both models can describe these two characteristics of price fluctuation well, indicating that the two models have the same information-fitting ability. Compared with the GARCH model, the GJR-GARCH model shows that negative information has a stronger impact on price fluctuations. The GJR-GARCH model has a stronger ability to capture information. The fitting ability of the two models is similar, and the GJR-GARCH model has a stronger ability to capture information. Therefore, the GJR-GARCH model is more suitable for depicting the price volatility characteristics of China's soybean futures market.

\subsection{Empirical Study on Dynamic Risk Based on VAR-GARCH} Measure Model. According to the above research, the variance-covariance method was adopted to measure risk. First, it is assumed that the series of return rates on assets obey a certain distribution, such as a normal distribution. Then, the parameter value of the return rate distribution is calculated by using the data of a certain period in the past, and finally, the asset value of the quantile is calculated at a certain confidence level. The calculation formula is as follows:

$$
\mathrm{VAR}=-Z_{c} \sigma_{\rho} \sqrt{\Delta t},
$$

where $Z_{c}$ represents the quantile of confidence level $C, \sigma_{\rho}$ represents the standard deviation of assets, and $t$ represents the holding period (i.e., the daily rate of return, $\Delta t=1$ ). When calculating the VAR value, we should first determine the $\sigma_{\rho}$ value. Owing to the characteristics of financial return series, such as sharp peaks and thick tails, volatility agglomeration, persistence, and leverage effect, we only process the mean value of the time series in the process of general simple model data processing and ignore the characteristics of the return series. Therefore, the GARCH $(1,1)$ model was selected according to the AIC and BIC after calculating the yield rate of the soybean futures A1505 contract, and the estimated $\sigma_{\rho}$ value in the model was put into the calculation formula of the VAR model. At this time, the $\sigma_{\rho}$ value can better reflect the characteristics of futures return rate, and the empirical analysis results are more reasonable and accurate.

According to the above analysis, the quantile, probability distribution, and conditional standard deviation under confidence must be obtained before calculating the value of VAR. The quantiles under $99 \%, 95 \%$, and $90 \%$ confidence were selected to calculate the risk value of the VAR-GARCH based on normal distribution. Under normal distribution, the daily yield sequences of China's soybean futures market are $2.3263,1.6449$, and 2.3263 with $99 \%$, 95\%, and $90 \%$ confidence levels, respectively.

$\sigma_{\rho}$ of the GARCH $(1,1)$ model and the quantile of different confidence degrees were put into the VAR 
TABLE 6: Comparison of GJR-GARCH $(p, q)$ model.

\begin{tabular}{|c|c|c|c|c|}
\hline & GJR-GARCH $(1,1)$ & GJR-GARCH $(1,2)$ & GJR-GARCH $(2,1)$ & GJR-GARCH $(2,2)$ \\
\hline $\mathrm{r}$ & $\begin{array}{c}0.371^{* * *} \\
(192.62)\end{array}$ & $\begin{array}{c}0.371^{* * *} \\
(192.95)\end{array}$ & $\begin{array}{l}0.369^{* * *} \\
(246.26)\end{array}$ & $\begin{array}{l}0.371^{* * *} \\
(196.42)\end{array}$ \\
\hline \multicolumn{5}{|l|}{$\mathrm{ARCH}$} \\
\hline L.arch & $\begin{array}{c}0.378^{* * *} \\
(10.33)\end{array}$ & $\begin{array}{l}0.378^{*} \\
(10.31)\end{array}$ & $\begin{array}{c}0.419^{* * *} \\
(13.24)\end{array}$ & $\begin{array}{c}0.364^{* *} \\
(9.31)\end{array}$ \\
\hline L2.arch & & & $\begin{array}{l}0.356^{* * *} \\
(-10.82)\end{array}$ & $\begin{array}{c}0.234^{* *} \\
(5.12)\end{array}$ \\
\hline L.gjr-garch & $\begin{array}{c}-0.0841 \\
(-1.38)\end{array}$ & $\begin{array}{c}-0.0788 \\
(-1.28)\end{array}$ & $\begin{array}{c}0.0453^{* * *} \\
(-5.38)\end{array}$ & $\begin{array}{c}-0.0529 \\
(-0.84)\end{array}$ \\
\hline L2.gjr-garch & & $\begin{array}{c}0.0133 \\
(0.59)\end{array}$ & & $\begin{array}{l}-0.0107 \\
(-0.20)\end{array}$ \\
\hline L.garch & $\begin{array}{c}-0.0237 \\
(-0.81)\end{array}$ & $\begin{array}{c}-0.0663 \\
(-0.92)\end{array}$ & $\begin{array}{c}0.962^{* * *} \\
(153.91)\end{array}$ & $\begin{array}{c}-0.759^{* * *} \\
(-10.14)\end{array}$ \\
\hline Cons & $\begin{array}{c}0.00345^{* * *} \\
(22.61) \\
\end{array}$ & $\begin{array}{c}0.00361^{* * *} \\
(13.52)\end{array}$ & $\begin{array}{c}0.00000252^{* * *} \\
(3.05) \\
\end{array}$ & $\begin{array}{c}0.00592^{* * *} \\
(16.89) \\
\end{array}$ \\
\hline $\mathrm{N}$ & 1219 & 1219 & 1219 & 1219 \\
\hline Log likelihood & 1589.9 & 1590.1 & 1646.4 & 1595.4 \\
\hline AIC & -3169.7 & -3168.1 & -3280.9 & -3176.8 \\
\hline $\mathrm{BIC}$ & -3144.2 & -3137.5 & -3250.3 & -3141.1 \\
\hline
\end{tabular}

$t$-statistics are given in parentheses. ${ }^{*} P<0.05,{ }^{* *} P<0.01$, and ${ }^{* * *} P<0.001$.

TABLE 7: Estimation of GJR-GARCH $(2,1)$ model.

\begin{tabular}{|c|c|c|c|c|c|}
\hline & $\alpha_{0}$ & $\alpha_{1}$ & $\alpha_{2}$ & $\beta_{1}$ & $\gamma$ \\
\hline Coefficient estimation & 0.0000252 & 0.4193364 & -0.3562949 & 0.9615618 & -0.0453458 \\
\hline$Z$ value & 3.05 & 13.24 & -10.82 & 153.91 & -5.38 \\
\hline$P$ value & 0.002 & 0.000 & 0.000 & 0.000 & 0.000 \\
\hline
\end{tabular}

calculation formula to calculate the risk value. The results are presented in Table 8.

According to Table 8, the mean, maximum, and minimum values of risks of different confidence levels in the two models can achieve a quantitative analysis of risks. In the GARCH $(1,1)$ model, at the $99 \%$ confidence level, the average risk is $-1.91 \%$, the maximum daily loss is not more than $-0.90 \%$, and the minimum loss is not less than $-11.20 \%$. At the $95 \%$ confidence level, the average risk is $-1.35 \%$, the maximum daily loss is not more than $-0.64 \%$, and the minimum daily loss is not less than $-7.92 \%$. At the $90 \%$ confidence level, the average risk is $-1.05 \%$, with a maximum daily loss of $-0.50 \%$ and a minimum daily loss of $-6.17 \%$. The following comparison diagram of VAR and return rate under different confidence levels of different models shows the comparison between VAR and actual returns more intuitively and clearly (Figure 3 ).

In Figure 3, k99 represents the VAR-GARCH model under $99 \%$ confidence, $\mathrm{k} 95$ represents the VAR-GARCH model under $95 \%$ confidence, k90 represents the VARGARCH model under $99 \%$ confidence, and $r$ represents the yield rate of China's soybean futures market. The comparison between risk volatility and the return rate at different confidence levels is shown in Figure 3. The risk value at the $90 \%$ confidence level was greater than that the $95 \%$ confidence level and at the $99 \%$ confidence level. Therefore, the failure rate was highest at the $90 \%$ confidence level. At the same time, the VAR value of China's soybean futures market also has a continuity and fluctuation agglomeration effect.

3.4. Empirical Study on Dynamic Risk Based on VAR-GJRGARCH Measure Model. The GJR-GARCH $(2,1)$ model was selected based on the AIC and BIC. The $\sigma_{P}$ value estimated in the model was incorporated into the calculation formula of the VAR model. The $\sigma_{P}$ value can better reflect the characteristics of the futures return rate, and the empirical analysis results are more reasonable and accurate.

According to the above analysis, the quantile, probability distribution, and conditional standard deviation under confidence should be obtained before calculating the value of VAR. The quantiles under 99\%, 95\%, and 90\% confidence, respectively, were selected to calculate the risk value of VARGJR-GARCH based on the normal distribution. $\sigma_{P}$ calculated by the GJR-GARCH $(2,1)$ model and the quantile under different confidence degrees were put into the VAR calculation formula to calculate the risk value. The results are presented in Table 9.

According to Table 9, we can see the mean value, maximum value, and minimum value of risks under different confidence levels in the two models, in order to achieve quantitative analysis of risks. In the GJR-GARCH $(2,1)$ model, at the $99 \%$ confidence level, the average risk is $-1.97 \%$, the maximum daily loss is not more than $-0.99 \%$, and the minimum loss is not less than $-7.39 \%$. At the $95 \%$ 
TABLE 8: Risk value calculation of the two models at different confidence levels.

\begin{tabular}{lccccc}
\hline Model & Degree of confidence (\%) & Mean & Standard deviations & Minimum & Maximum \\
\hline & 99 & -0.0190769 & 0.0077497 & -0.111965 & -0.0090189 \\
VAR-GARCH & 95 & -0.013489 & 0.0054798 & -0.0791691 & -0.0063772 \\
& 90 & -0.0105098 & 0.0042695 & -0.0616835 & -0.0049687 \\
\hline
\end{tabular}

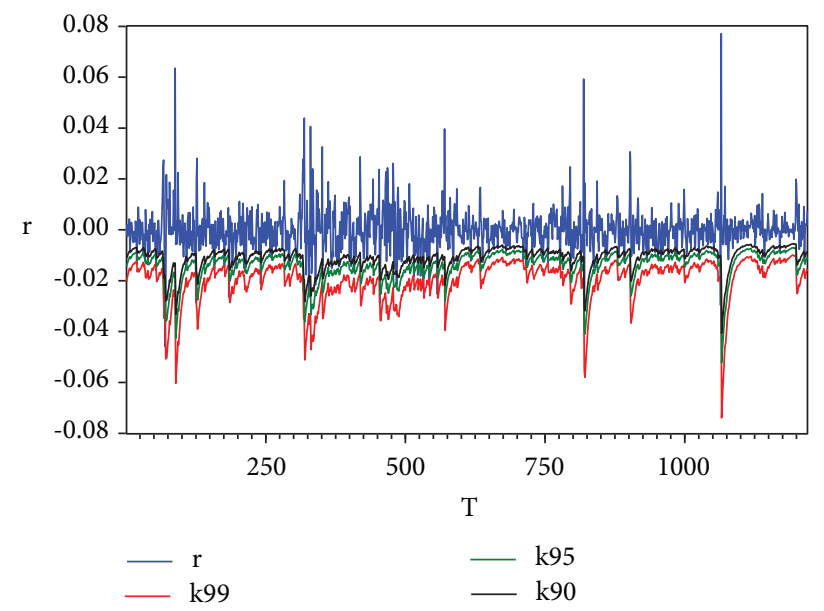

FIGURE 3: Comparison of VAR-GARCH model risk value and return rate at different confidence levels.

TABLE 9: Risk value calculation of the two models at different confidence levels.

\begin{tabular}{lcccrc}
\hline Model & Degree of confidence (\%) & Mean & Standard deviations & Minimum & Maximum \\
\hline & 99 & -0.0196874 & 0.0080489 & -0.0738947 & -0.0098829 \\
VAR-GJR-GARCH & 95 & -0.0139207 & 0.0056913 & -0.0522501 & -0.0069881 \\
& 90 & -0.0108461 & 0.0044343 & -0.0407099 & -0.0054447 \\
\hline
\end{tabular}

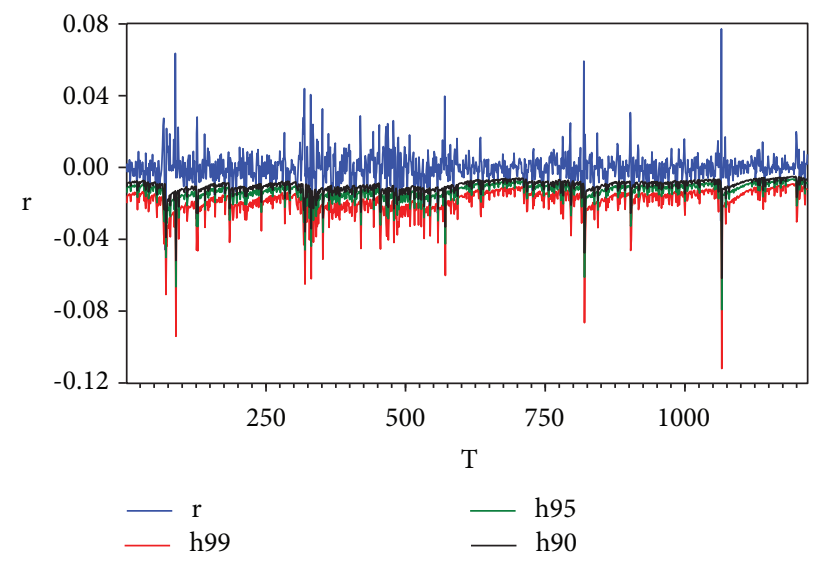

Figure 4: Comparison of VAR-GJR-GARCH model risk value and return rate at different confidence levels.

confidence level, the average risk is $-1.35 \%$, the maximum daily loss is not more than $-0.64 \%$, and the minimum daily loss is not less than $-7.92 \%$. At the $90 \%$ confidence level, the average risk is $-1.08 \%$, with a maximum daily loss of no more than $-0.54 \%$ and a minimum daily loss of no less than $-4.07 \%$. To observe the comparison between VAR and actual returns more intuitively and clearly, a comparison diagram of VAR and return rate under different models and different confidence levels was drawn (Figure 4).
In Figure 4, h99 represents the VAR of the VAR-GJRGARCH model with $99 \%$ confidence. H95 represents the VAR of the VAR-GJR-GARCH model with 95\% confidence. H90 represents the VAR of the VAR-GJR-GARCH model with $99 \%$ confidence. $r$ represents the rate of return on China's soybean futures market. A comparison between risk volatility and return rate at different confidence levels is clearly shown. The risk value at the $90 \%$ confidence level is greater than that at the $95 \%$ confidence level and at the $99 \%$ 


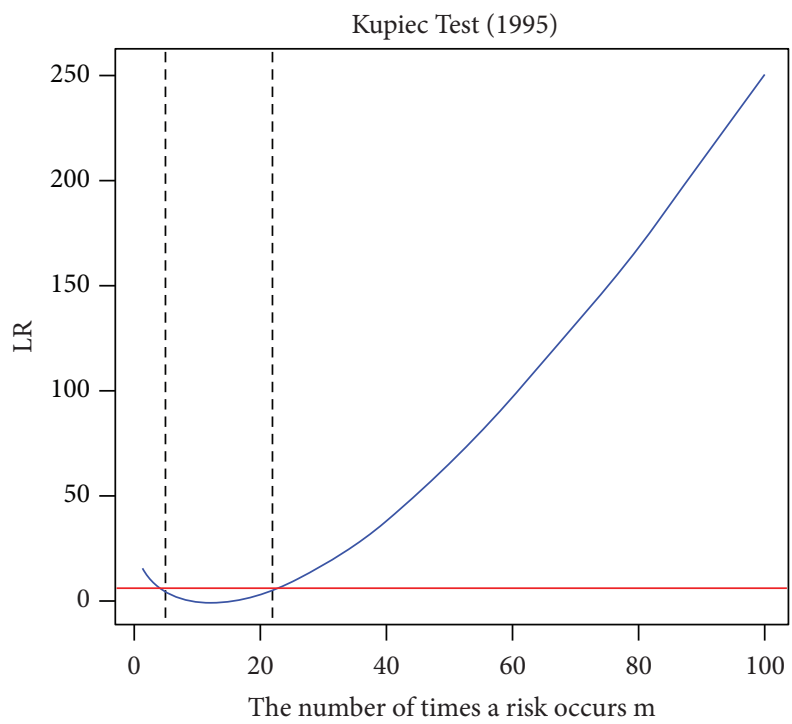

Figure 5: Interval chart of risk days at $99 \%$ confidence level.

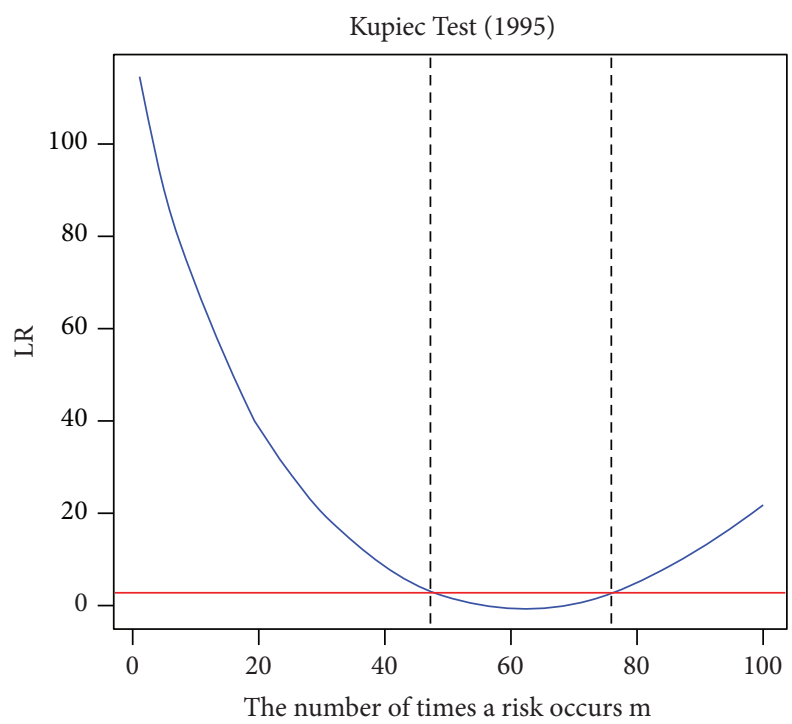

Figure 6: Interval chart of risk days at $95 \%$ confidence level.

confidence level. Therefore, the failure rate was the highest at a $90 \%$ confidence level. However, the failure rate cannot directly reflect the rationality of the model, and the failure days under the condition of the confidence level should be measured. Therefore, the failure rate test of the VAR model was used to verify the rationality of the model.

3.5. Dynamic Risk Model Measure Effect. Many risk assessment methods have been developed. The failure rate test method, which mainly tests the probability that the actual loss exceeds the VAR, was adopted. Kupiec proposed the failure rate test method. Its main idea is to record days in which the actual loss value exceeds the VAR estimate as failure days and then calculate the failure rate [16]. Because the estimation is assumed to be time-independent, the test of the binomial result under the failure condition can be regarded as an independent Bernoulli experiment; therefore, the expected failure probability is denoted as $P^{*}$. The interval of failure days is different at different confidence levels, and the failure days within the interval of failure days at a given confidence level indicate that the VAR value is valid. If the observation days in the model are $T$ and the failure days are $N$, then the failure rate is $p=N / T$, and the null hypothesis is $p=p^{*}$. The most appropriate method for testing $\mathrm{A}$ is the maximum likelihood ratio test. The formula is as follows:

$$
\mathrm{LR}=-2 \ln \left[\left(1-p^{*}\right)^{T-N}\left(p^{*}\right)^{N}\right]+2 \ln \left[\left(1-\frac{N}{T}\right)^{T-N}\left(\frac{N}{T}\right)^{N}\right] .
$$

Under the null hypothesis, the statistic obeys $\mathrm{LR} \sim \chi^{2}(1)$. This test method tends to underestimate potential risks in small sample data. Therefore, this study 


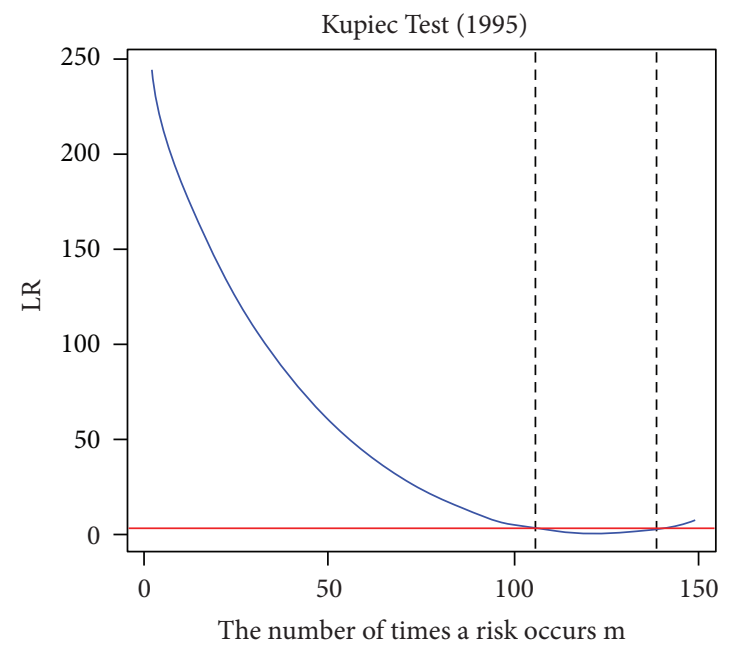

Figure 7: Interval chart of risk days at $90 \%$ confidence level.

TABLe 10: Failure rate test of the two models at different confidence levels.

\begin{tabular}{|c|c|c|c|c|c|}
\hline Degree of confidence (\%) & Failure day interval & Model & Actual failure days & Failure rate & Whether it passes the test \\
\hline \multirow{2}{*}{99} & \multirow{2}{*}[4,22]{} & VAR-GARCH & 17 & 0.013945857 & Yes \\
\hline & & VAR-GJR-GARCH & 14 & 0.011484824 & Yes \\
\hline \multirow{2}{*}{95} & \multirow{2}{*}[48,77]{} & VAR-GARCH & 52 & 0.042657916 & Yes \\
\hline & & VAR-GJR-GARCH & 55 & 0.04511895 & Yes \\
\hline \multirow{2}{*}{90} & \multirow{2}{*}[106,139]{} & VAR-GARCH & 100 & 0.082034454 & Yes \\
\hline & & VAR-GJR-GARCH & 100 & 0.082034454 & Yes \\
\hline
\end{tabular}

adopts a large sample of data, which can effectively avoid this situation.

According to the failure rate test formula and method, the failure day intervals were calculated at 99\%, 95\%, and $90 \%$ confidence levels. The corresponding graphs of the failure days $M$ and LR were drawn. The interval at which the curve intersects the line is the confidence interval of the number of failure days. When the failure days are within the interval under a certain confidence degree, the null hypothesis is accepted, indicating that the risk measure is reasonable. If the number of failure days is lower than the minimum value of the interval, the model estimate is too conservative. If the number of failure days is greater than the maximum value of the model, the model underestimates the risk. The results are shown in Figures 5-7.

In Figures 5-7, the days of risk represent the days of risk under 99\%, 95\%, and 90\% confidence, respectively. The dynamic VAR values obtained by the two models at different confidence levels were compared with the daily actual return rate. The part where the daily real return rate is lower than the VAR value is recorded as the actual failure days. The accuracy of the model was judged according to the interval values under different degrees of confidence. The results are presented in Table 10.

According to Table 10, the following conclusions can be drawn:

(1) At the 99\% confidence level, the actual failure days of the VAR-GARCH model and the VAR-GJR-
GARCH model both fall within the range of the failure days estimated by the model, and the failure rates pass the test, indicating that the two models can better measure the risk at the $99 \%$ confidence level.

(2) At the 95\% confidence level, the actual failure days of the VAR-GARCH model and the VAR-GJRGARCH model both fall within the range of the failure days estimated by the model, and the failure rates pass the test, indicating that the two models can better measure the risk at the $95 \%$ confidence level. There is little difference between the two models in the measurement of risk, and at the $90 \%$ confidence level, the failure rates of the two models are the same, so neither model can estimate the value of risk. Therefore, participants in China's soybean futures market can conduct risk measurement research at $99 \%$ and $95 \%$ confidence levels according to the two models to estimate the value of risk and effectively avoid non-systemic risks.

\section{Conclusions}

China's soybean futures market started late, and the price fluctuated violently, so there was a large risk. In this study, the VAR-GARCH and VAR-GJR-GARCH models were first constructed to measure the risk value at $99 \%, 95 \%$, and $90 \%$ confidence levels, and then the risk was measured by quantitative analysis. Next, the accuracy and rationality of 
the model estimation were measured using the failure rate test method. Finally, the risk value calculated by the two constructed models at $99 \%$ and $95 \%$ confidence levels is more valuable, which can better measure the risk of the Chinese soybean futures market. For futures markets with higher risk tolerance or when the risk-bearing ability is low for participants, the combined model can undertake the risk measure to avoid risks, to some extent, for futures market participants. Empirical research on the two types of combination models can be better applied to calculate risk measures in the soybean futures market. At the same time, the government can formulate corresponding countermeasures according to risk value to effectively avoid risks and promote the stable development of China's soybean futures market.

Although this paper studies the price risk measurement of China's soybean futures from a variety of perspectives and has made some achievements, there is still a lot of work to be done to further understand the price risk. The specific shortcomings and prospects are as follows:

(1) Although compared with other risk measurement models, the VAR method can better measure the risk value, this paper describes more accurately through the GARCH class model, but there exit still shortcomings. Compared with futures markets with greater risks, extreme situations occur in a high frequency. It is difficult to calculate the future VAT risk by using the VAR method in advance and predict the future VAT risk by using the historical rate of return, which cannot reflect the mood changes of market traders. Therefore, in our next step of research, macro-environmental changes will be taken into account in time, and the model established above should be adjusted in time. Traders' emotions should be taken into account in order to carry out more accurate risk measurement.

(2) The daily high-frequency data selected in this paper can better reflect the volatility. For in-sample data, the prediction accuracy is high. For out-of-sample prediction, only a few data can be predicted to ensure the data accuracy, and the daily high-frequency data can only be predicted for a few days. Therefore, monthly data and quarterly data will be considered in the future research, compared with daily data for comparative analysis. This work will characterize price risk more comprehensively and profoundly.

\section{Appendix}

$\mathrm{R}$ programming: $n<-1219 ; m<-$ seq (from $=1$, to $=100$, length $=100)$; $p<-0.01$; \#The probability of exceptions occurring. conf $<-0.99$; \# The confidence level of the $\mathrm{chi}^{\wedge} 2$ distribution.

$\mathrm{LR}=-2^{*} \log \left(\left((1-p)^{\wedge}(n-m)\right)^{*} \quad\left(p^{\wedge} m\right)\right)+2^{*} \log (((1-(m)$ $\left.\left.n))^{\wedge}(n-m)\right)^{*}\left((m / n)^{\wedge} m\right)\right)$; critical_value $<-$ qchisq (conf, 1$)$; plot $(m, \mathrm{LR}$, type $=$ "l," col = "blue," lwd $=2$, main = "Kupiec Test (1995)," xlab = "The number of times a risk occurs m") abline ( $\mathrm{h}=$ critical_value, $\mathrm{col}=$ "red," lwd $=3$ ).

LR_C $<-$ which (LR $\leq$ critical_value).

abline $(v=c($ LR_C $[1], \quad$ LR_C [length (LR_C)] ), lty = "dashed")

LR_C.

$n<-1219 ; m<-$ seq (from $=1$, to $=100$, length $=100$ );

$P<-0.05$; \# The probability of exceptions occurring.

conf $<-0.95$; \# The confidence level of the chi $\wedge_{2}$ distribution.

$\mathrm{LR}=-2^{*} \log \left(\left((1-p)^{\wedge}(n-m)\right)^{*} \quad\left(p^{\wedge} m\right)\right)+2^{*} \log (((1-(m /$

$\left.\left.n))^{\wedge}(n-m)\right)^{*}\left((m / n)^{\wedge} m\right)\right)$; critical_value $<-$ qchisq (conf, 1$)$;

plot $(m, \mathrm{LR}$, type $=$ "l," col = "blue," lwd $=2$, main = "Kupiec

Test (1995)," xlab = "The number of times a risk occurs m") abline ( $\mathrm{h}=$ critical_value, $\mathrm{col}=$ "red," lwd $=3$ ).

LR_C $<-$ which (LR $\leq$ critical_value).

abline $\quad(v=c \quad$ (LR_C[1], LR_C[length(LR_C)]), lty $=$ "dashed")

LR_C.

$n<-1219 ; m<-$ seq (from $=1$, to $=150$, length $=150$ );

$P<-0.10$; \# The probability of exceptions occurring.

conf $<-0.90$; \# The confidence level of the chi ${ }^{\wedge} 2$ distribution.

$\mathrm{LR}=-2^{*} \log \left(\left((1-p)^{\wedge}(n-m)\right)^{*}\left(p^{\wedge} m\right)\right)+2^{*} \log (((1-(m /$

$\left.\left.n))^{\wedge}(n-m)\right)^{*}\left((m / n)^{\wedge} m\right)\right)$; critical_value $<-$ qchisq (conf, 1$)$; plot $(m$, LR, type $=$ "l," col = "blue," lwd $=2$, main = "Kupiec

Test (1995)," xlab = "The number of times a risk occurs m") abline ( $\mathrm{h}=$ critical_value, $\mathrm{col}=$ "red," lwd $=3$ ).

LR_C $<-$ which (LR $\leq$ critical_value).

abline $\quad(v=c($ LR_C[1], $\quad$ LR_C[length(LR_C $)])$,

lty $=$ "dashed")

LR_C.

\section{Data Availability}

The data used to support the findings of this study are available at https://www.gtarsc.com/.

\section{Conflicts of Interest}

The authors declare that they have no conflicts of interest.

\section{Acknowledgments}

This research was funded and supported by the Science Foundation of Ministry of Education of China (grant no. 19YJC790128). The authors are grateful to all the individuals who conducted data collection and data entry. The authors would like to thank Editage (http://www.editage.cn) for English language editing.

\section{References}

[1] H. Markowitz, "Portfolio selection," The Journal of Finance, vol. 7, no. 1, pp. 77-91, 1952.

[2] T. Bolleslev, "Generalized autoregressive conditional heteroskedasticity," Journal of Econometrics, vol. 31, no. 3, pp. 307-327, 1986. 
[3] J. J. Zou, Z. Y. Zhang, and Z. Qin, "Research on the application of GARCH model to calculate the value at risk of stock market in China," Systems Engineering Theory and Practice, vol. 05, pp. 20-25+135, 2003.

[4] Y. Liu and Z. Yu, "Experience and reference of agricultural product price risk management using futures market in the United States," Chinese Rural Economy, vol. 05, pp. 65-72, 2008.

[5] H. Jiang and D. D. Qu, "An empirical study on risk management of CSI 300 stock index futures based on VaR," Economic Problems, vol. 12, pp. 119-122, 2008.

[6] F. L Yang, "An empirical study on VaR calculation of securities Investment fund based on GARCH Model," Economic Problems, vol. 394, no. 6, pp. 87-91, 2012.

[7] C. Zhang, Y. Ding, and W. J. Wang, "An innovation of estimating value at risk of international carbon market: conditional autoregressive value at risk model with refinements from extreme value theory," Chinese Journal of Management Science, vol. 23, no. 11, pp. 12-20, 2015.

[8] S. G. Tao and J. Y. Chen, "China's Foreign exchange reserve safety management stress test and Empirical Analysis," Finance and Economics, vol. 346, no. 1, pp. 1-11, 2017.

[9] Q. Yang and J. J. Yang, "The ripple spillover effect between Shibor online lending rate and private lending rate," Research in Financial Economics, vol. 33, no. 4, pp. 14-23, 2018.

[10] M. Karmakar and S. Paul, "Intraday portfolio risk management using VaR and CVaR:A CGARCH-EVT-Copula approach," International Journal of Forecasting, vol. 35, no. 2, pp. 699-709, 2019.

[11] W. H. Lin, M. Q. Chen, L. G. Zhou, and X. X. Meng, “Analysis of risk prediction ability of Chinese stock market based on Var-GARCH model family," Statistics \& Decisions, vol. 35, no. 21, pp. 151-155, 2019.

[12] X.-L. Gong, X.-H. Liu, and X. Xiong, "Measuring tail risk with GAS time varying copula, fat tailed GARCH model and hedging for crude oil futures," Pacific-Basin Finance Journal, vol. 55, no. 55, pp. 95-109, 2019.

[13] C. Liu and B. B. Liu, "Spillover effects of financial institutions' tail risks: an improved asymmetric CoVaR model," Statistical Research, vol. 37, no. 12, pp. 58-74, 2020.

[14] Y. Liang, "Innovation and application of rebar futures hedging method -- analysis based on GJR-GARCH-VAR model," Price Theory and Practice, vol. 434, no. 8, pp. 108-111, 2020.

[15] C. Alexander, E. Lazar, and S. Stanescu, "Forecasting VaR using analytic higher moments for GARCH processes," International Review of Financial Analysis, vol. 30, no. 30, pp. 36-45, 2013.

[16] P. H. Kupiec, "Techniques for verifying the accuracy of risk measurement models," Journal of Derivatives, vol. 3, no. 2, pp. 73-84, 1995. 